\title{
Bite force and dental implant treatment: a short review
}

\section{Dennis Flanagan ${ }^{1,2}$ \\ 'Department of Dental Medicine, Implantology LUdeS Foundation, Ricasoli, Malta; ${ }^{2}$ Private Practice, Willimantic, CT, USA}

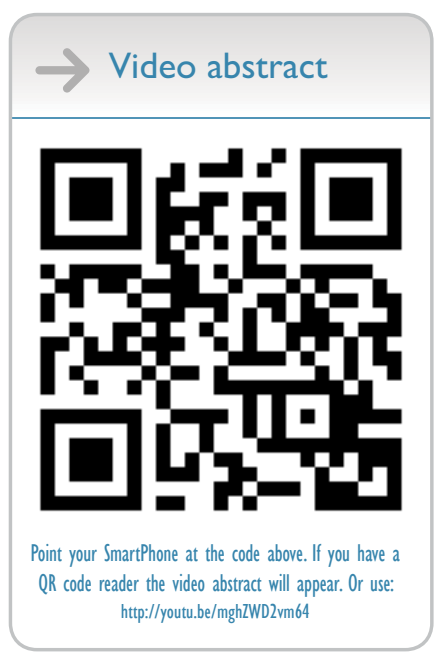

Correspondence: Dennis Flanagan I67I Main St., Willimantic, CT 06226, USA

Tel + I 8604563153

Fax +l 8604568759

Email dffdds@comcast.net
This article was published in the following Dove Press journal:

Medical Devices: Evidence and Research

27 June 2017

Number of times this article has been viewed

\begin{abstract}
Dental implants are placed endosseously, and the bone is the ultimate bearer of the occlusal load. Patients are not uniform in the maximum bite force they can generate. The occlusal biting load in the posterior jaw is usually about three times of that found in the anterior. It is possible for supporting implants to be overloaded by the patients' biting force, resulting in bone loss and failure of the fixture. Bite force measurement may be an important parameter when planning dental implant treatment. Some patients can generate extreme biting loads that may cause a luxation of the fixture and subsequent loss of osseointegration. A patient with low biting force may be able to have a successful long-term outcome even with poor anatomical bone qualities. Patients with a high bite force capability may have an increased risk for late component fracture or implant failure. There is no correlation of any bite force value that would indicate any overload of a given implant in a given osseous site. Nonetheless, after bite force measurement, a qualitative judgement may be made by the clinician for the selection of an implant diameter and length and prosthetic design.
\end{abstract}

Keywords: occlusal load, newtons, oral function, force, sensor, software

\section{Introduction}

A major indicator of the functional state of the masticatory system is the generated biting force. ${ }^{1}$ The ability to bite is a function of the craniomandibular structures, including the muscles of mastication, the temporomandibular joint and the dentition, be it natural or artificial. ${ }^{1}$

Biting and eating is an interaction of the physical properties of food and the mastication complex. ${ }^{2}$ The mechanical factors of this interaction, where muscle contraction adaption to the food texture and density, are largely unknown. ${ }^{2}$ The initial encounter of the jaws with the food is the factor that determines the subsequent muscle force in mastication. ${ }^{2}$ Slow jaw velocity induces a low bite force for mastication. ${ }^{2}$ Appropriate mastication is a quality-of life-issue, and the primary goal of implant supported dental rehabilitation.

In the course of dental implant treatment, failures are to be expected. Failures can occur early or late in treatment. There is controversy as to the causes for failures. Nonetheless, one cause for failure can be occlusal overload. ${ }^{3,4}$ Human mastication, dietary habits and parafunctional loads are cyclic and multidirectional and of variable magnitudes. ${ }^{5-7}$ The posterior human bite force magnitude is about three times that of the anterior. ${ }^{7}$

Off-axial loads can be detrimental for a dental implant that is not embedded in an adequate thickness of cortical bone. ${ }^{7-9}$ To address an overload potential, it may be 
important to measure the maximal biting load a patient can generate. If the clinician suspects a potential for an overload, then a more substantial implant may be planned. This may be especially true when treating the anterior maxilla where almost all loading is inherently off axial.

The importance of bite force and its measurement for dental implant rehabilitation may become an integral part of the complete oral examination..$^{10,11}$

\section{Materials and methods}

A MEDLINE PubMed literature search was made using the keywords: "jaw biting force AND bite load" and "bite force measurement". Ninety-seven articles were retrieved, and 30 were deemed appropriate and discussed herein as well as additional articles deemed required for citation evidence.

\section{Case example}

A 70-year-old male, with an unremarkable medical history and missing maxillary posterior teeth, desired a fixed partial denture to facilitate his prandial life pleasures. A complete oral clinical and radiographic examination was performed. A pneumatized antrum precluded implant placement at the maxillary left second premolar and first molar sites without augmentation. The patient declined a sinus floor elevation osseous augmentation to provide osseous volume to these sites. A long-span two-implant-supported fixed partial denture was planned for an anterior guidance occlusal scheme and treatment implemented. A $3.7 \times 10 \mathrm{~mm}$ anterior implant and a $5.7 \times 8 \mathrm{~mm}$ distal implant were used (Figure 1). After 3 months of uneventful service, the anterior-most implant failed. The distal implant did not fail. An anterior guided occlusal scheme directs the bite forces axially, but the facial excursion of the lower jaw can place lateral loads on the anterior-most implant.

A bite force measurement was taken and surprisingly was found to be 1,200 newtons $(\mathrm{N})$, well above the published usual maximal of $900 \mathrm{~N}$. After removal and debridement, a larger diameter and longer $(4.7 \times 13 \mathrm{~mm})$ mesial implant was placed, and after healing, a new fixed partial denture was fabricated and delivered (Figures 2 and 3). This prosthesis has had 2 years of uneventful service with no failure or unusual bone loss.

The patient in the case example has provided written informed consent for publication of the case details including images to this review.

\section{Discussion}

The biting force that a given patient is able to deliver may be an issue in case planning for oral rehabilitation. An assessment

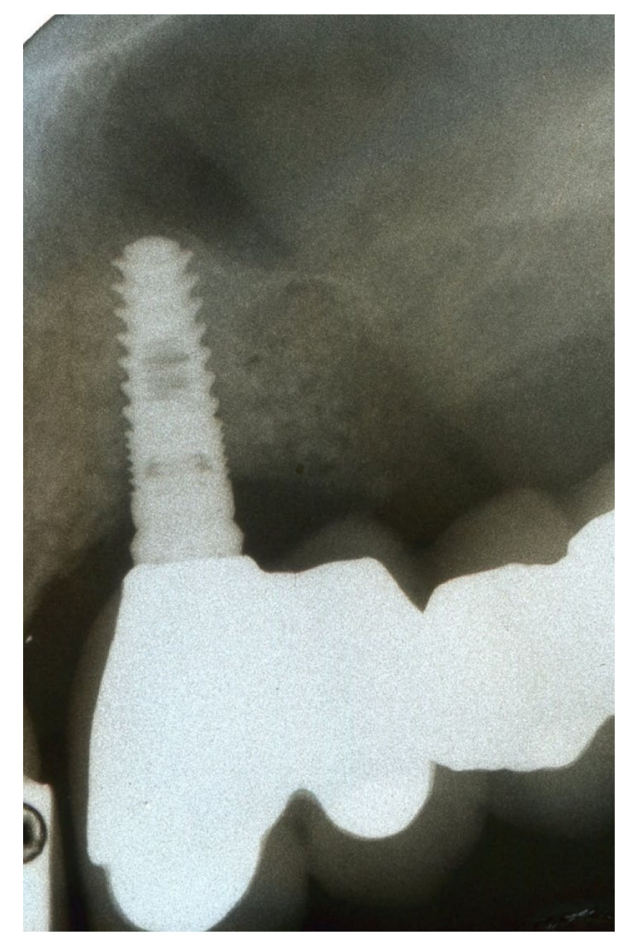

Figure I A $3.7 \times 10 \mathrm{~mm}$ implant was placed and found to be inadequate to resist the patient's extreme occlusal load of $1,200 \mathrm{~N}$.

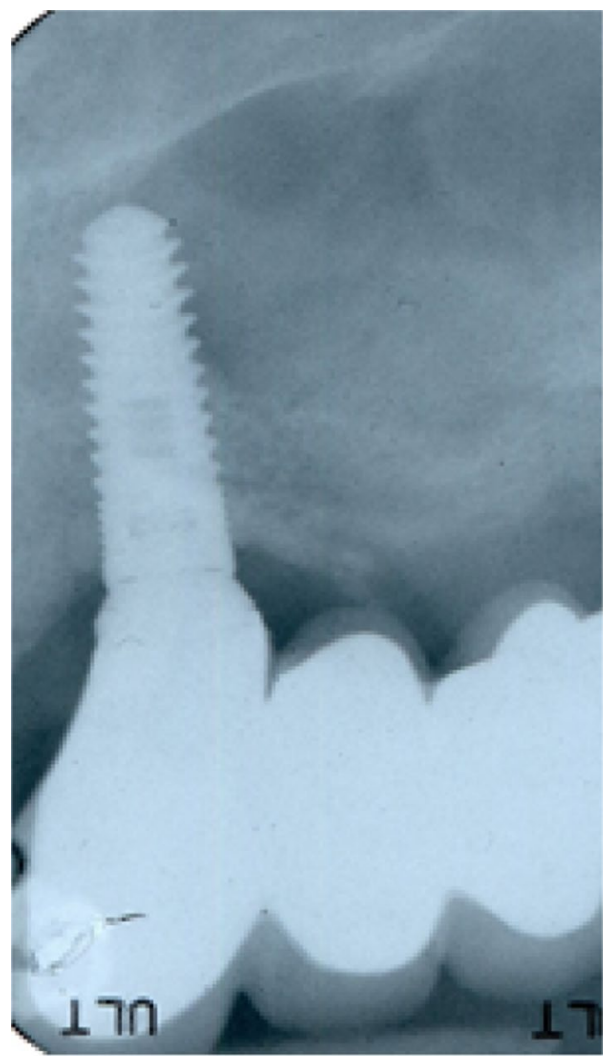

Figure $2 \mathrm{~A}$ larger and longer implant was placed to support the long-span fixed partial denture.

of the occlusal scheme, bone quality, volume, dietary habits, parafunction and patient biting force may be considered the parameters for implant treatment. Some studies show that 


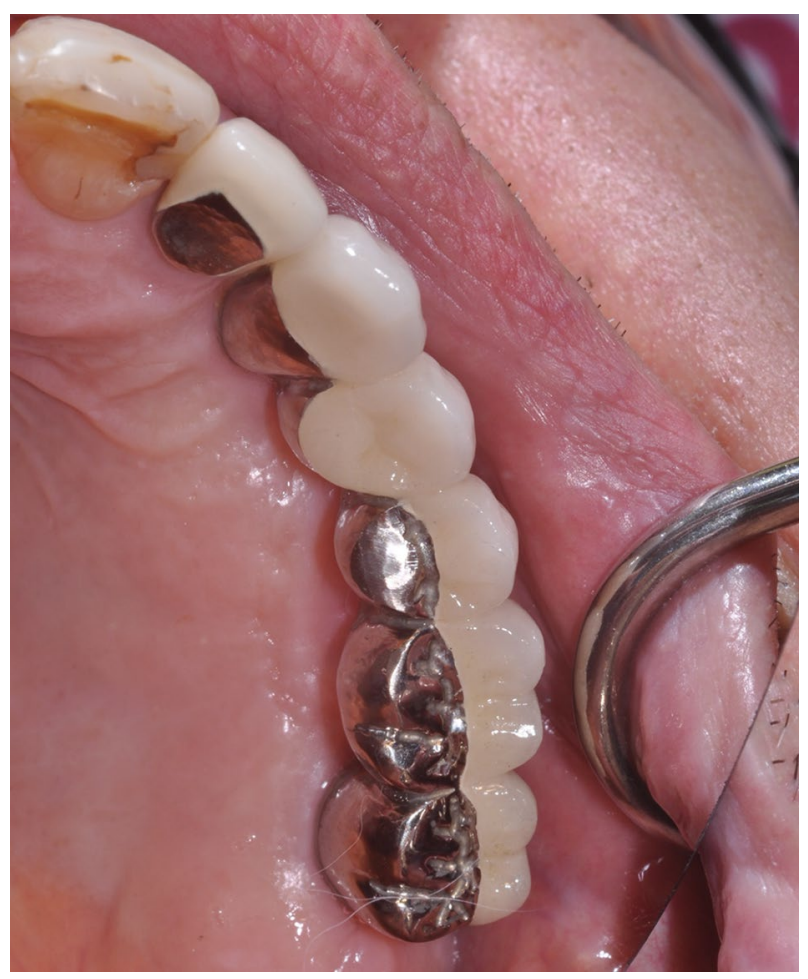

Figure 3 Two years of successful loading has occurred.

dental patients can generally deliver a maximum jaw force in a range of 50-900N..$^{1,12}$ However, the upper limit found in these studies may be in error. Anecdotally, this author has found a few outlying patients who can generate $>900 \mathrm{~N}$.

Dentate patients develop osseous stress that causes apposition for increased osseous density around natural teeth. Under low loads, osseous apposition around dental implants can also occur. ${ }^{13}$ Under high loads, implants can experience bone resorption or fracture. ${ }^{13}$ Measuring this maximum force parameter may be important for implant selection and for prosthetic and occlusal design.

Occlusal forces are distributed through the mid-face skeleton in five vertical and two horizontal buttress planes. ${ }^{14}$ The buttress planes are the nasomaxillary, zygomaticomaxillary, pterygo-maxillary, sagittal, frontal, zygomatic and maxillary. These osseous buttress planes resist the patient's jaw force.

Cortical bone has been shown to be the primary support in the maxillary anterior. ${ }^{14}$ However, both cortical and trabecular bones are equally involved in load resistance in the posterior maxilla. ${ }^{14}$ Nonetheless, osseous quality remains as the primary parameter for implant support. ${ }^{14}$

Loss of periodontal osseous support in natural teeth does not reduce bite force capability. ${ }^{15}$ Thus, jaw bite force is muscle dependent and not tooth support or proprioception dependent. ${ }^{15}$

Dental implant-supported prostheses are successful in functional occlusal loading, but still jaw forces are borne ultimately by the supporting bone. ${ }^{7,816}$ Control of these forces by a well-designed occlusal scheme is an important parameter in treatment planning. Ascertaining the numerical value of a given patient's maximum jaw biting force capability can be used to design an occlusal scheme and an array of implant size, number and position. However, the clinical assessment of a bite force value is obscure.

Various jaw positions induce activity in different muscles. In edge-to-edge jaw position, incisal loading induces masseter muscle activity. ${ }^{16}$ The masseter muscles also dominate the action of the temporalis muscles during submaximal incisal biting function. ${ }^{16}$ The relative activity of other muscles of mastication during function is difficult to measure due to their deep anatomical location.

Chronic and excessive incisal loads can induce stress to the temporomandibular joint (TMJ) complex. ${ }^{16}$ Thus, patients who can generate excessive loads may induce a TMJ strain. ${ }^{16}$ Additionally, "habitual chewing side syndrome" is a favoring of chewing on one jaw side characterized by a steeper condylar path, flatter lateral anterior guidance and habitual chewing on the symptomatic jaw side. ${ }^{17}$

Implant design affects peri-implant bone stress in the anterior maxilla. ${ }^{18}$ Implant designs with platform switching cause lower osseous stresses and strains than other implant designs. ${ }^{19}$ This design induces less osseous strain than other designs with a patient with an increased biting load and thus may have less risk for marginal bone loss and overloading. ${ }^{19}$

A high bite force can result in fractured implant components. ${ }^{20} \mathrm{~A}$ cyclic off-axial force is capable of causing an abutment screw fracture. ${ }^{20}$ Patients with a high bite force may have an increased risk for component fracture. ${ }^{20}$

Patients with conventional removable non-implantedentulous-ridge-supported complete dentures do not deliver as much of a load as compared to dentate patients. ${ }^{21}$ However, implant-retained complete overdentures enable higher occlusal forces than conventional complete dentures. ${ }^{21}$ There is improved stability and enhanced masticatory function with implant retention and support. In distal extensions, the implant-retained overdentures have a higher hydrostatic stress on mucosa at the posterior mandible. ${ }^{21}$ The distal of the complete denture is in effect a cantilever when there is anterior implant retention. Hydrostatic pressure on the underlying mucosa correlates with bone resorption, which can induce mandibular ridge resorption..$^{21}$ The mean bone height loss after 10 years can be $0.5 \mathrm{~mm} \cdot{ }^{13,21}$ Nonetheless, control of occlusal loading by the occlusal scheme may help to minimize osseous resorption. ${ }^{21}$ Removable prosthetic occlusal schemes are limited by the remaining osseous 
support, soft tissue and patient accommodation, among other factors. Interestingly, even if there is bone volume loss, bone density may be increased. ${ }^{13,21}$

Generally, a group function or lingualized occlusion is appropriate for removable dentures, but some patients do function with an anterior guided scheme. An anterior guided scheme directs the load to the anterior teeth where the loading force is about a third of that of the posterior region. Nonetheless, a high occlusal force can over load the anterior teeth or supporting bone. ${ }^{5}$

Functioning of implant supported prosthetics is subjected to variable loads in direction and magnitude, and the occlusal scheme should direct the loads so as to minimize the ridge contact. $^{7,8}$

Some patients are capable of delivering a range of bite loads that may affect the longevity of implant-supported prostheses. ${ }^{7,8}$ Supporting bone of adequate volume and density is very able to resist axial loads. ${ }^{7}$ Nonetheless, offaxial loads may not be as well tolerated, and the supporting bone quality is the important issue here. ${ }^{7,8} \mathrm{~A}$ circumferential bone thickness of 1.8-2.0 mm may be required for a longterm functional and esthetic outcome. ${ }^{9}$ Off-axial loads are directed to the four anatomical directions: mesial, distal, lingual and facial. Interproximal bone is generally dense and thick especially if there are natural teeth that are adjacent or a broad volume of supportive bone. ${ }^{9}$ Interproximal bone does not have a facial or lingual osseous fossa or an apical concavity. ${ }^{22}$ Lingual bone is generally thicker than facial bone and thus is more supportive and more likely able to resist off-axial loads. ${ }^{22}$

Anterior facial cortical bone generally is thinner or absent and resorbs as socket healing progresses from the apex of the healing socket. ${ }^{22}$ Poor healing may result in a site that provides poor resistance to facial off-axial loads due to a thin poorly supportive cortex..$^{22}$ There will be no buttressing that would be provided by thick cortical bone. Thick lingual bone or a broad proximal expanse of an edentulous ridge can provide adequate support for loads directed in these directions. Thus, thin facial bone may be prone to microfracture and resorption under off-axial loads and lead to early or late implant failure. ${ }^{9}$ Thus, the density and thickness of the facial bone may be the most important factors in long-term function because off-axial loads directed toward the facial may be most at risk for an overload. ${ }^{9}$ Nonetheless, a patient with a very low generated jaw force may be able to have a successful prosthesis supported by low-volume or poor quality bone. Nonetheless, the critical event value of a biting load for a particular osseous density is not known.
The axial and buffered loading of mini implants that retain a complete mandibular overdenture may not cause marginal bone loss. ${ }^{23}$ One study of two mini implants $(1.8 \times 15 \mathrm{~mm})$ retaining a complete mandibular overdenture did not demonstrate marginal bone loss even after 15 months of function. ${ }^{23}$ The mini implants in this study were very narrow $(1.8 \mathrm{~mm})$ but very long $(15 \mathrm{~mm})$. Loads on these implants may be less because removable complete denture patients do not generate as great a load as dentate patients. The denture retainers are soft and give under load, thus buffering or damping the load stress. Nonetheless, bite force measurement in these patients may aid in treatment design for a successful prosthesis. Patients with high bite force capability may overload narrow diameter implants and need longer or wider implants to resist the delivered higher load.

Off-axial loading may be an issue for implant or component fracture. ${ }^{19}$ In the anterior maxilla where all loads are off axial, measurement of these patient's bite force may indicate the use of wider diameter implants or implant splinting to better resist this type of load. In one in vitro study, an off-axial load of $>250 \mathrm{~N}$ resulted in fracture of the abutment screw or the implant cervical. ${ }^{19}$ Thus, a preoperative bite load measurement may prevent late prosthetic complications by increasing the number or size of the supporting implants.

A patient's diet and bite force load may work in tandem to overload an implant-supported prosthesis. For example, some patients have a chronic popcorn habit that may induce an off-axial over load. ${ }^{5}$ A patient with high bite force may overload implants, especially from crunching on un-popped kernels. A patient with low biting load may have a successful prosthesis regardless of any detrimental eating habits or parafunction.

The patient's state of mind may influence the ability to measure the maximum force. ${ }^{11}$ During the measurement of a bite force, patient reluctance to cooperate or fatigue may cause a reduced reading. ${ }^{11}$

At prosthetic delivery, leaving the occlusal surface approximately 30 microns short of the opposing contact does not appear to significantly reduce loading during food mastication. ${ }^{24}$ It is the practice of many dentists to leave a slight occlusal gap to prevent the sole occlusal contact of the implant crown during functional intrusion of the adjacent natural teeth. The hope is to lessen the loading impact on the prosthesis in parafunction. Nevertheless, this may not lessen the load created during mastication.

Taken together, all the physiologic treatment planning parameters may be significantly influenced by a very high 
or very low bite force. With a low force, the bone can be less dense and still tolerate the occlusal load. An anterior guided scheme may be tolerated, prosthetic teeth can be esthetically ramped, implants can be placed off axially without detriment and narrow diameter implants may be used. It remains to be seen that loads can be successfully tolerated by a high bite force.

\section{Bite force measurement devices}

Bite force can be easily measured using any of several devices available. $^{10}$

One device measures the submaximal bite force with a sensor and a strain gauge bite fork. ${ }^{1}$ This device reported a range of $50-800 \mathrm{~N}$ with a $93 \%$ reliability. ${ }^{1}$

Another electrically passive device safe for intraoral use is a fiber Bragg grating bite force recorder. ${ }^{25}$ It has a measurement range of $0-900 \mathrm{~N}^{25}$ This is calibrated with a Micro Universal Testing Machine (UTM) to a resolution of $0.54 \mathrm{~N}$. A measured range of $176-635 \mathrm{~N}$ was found. ${ }^{25}$

Another device comprises a quartz force transducer sensor and a microprocessor with a liquid crystal display (LCD), contained in a steel housing. ${ }^{12}$ This device measured a mean maximal bite force of $847 \mathrm{~N}$ for men and $597 \mathrm{~N}$ for women. All readings were taken in the posterior jaw. ${ }^{12}$

A piezoelectric device uses a flexible polyimide electrode and barium titanate-based multilayer ceramic capacitors. ${ }^{26}$ This sensor has high fracture strength and good sensing properties. This low-cost device has a $5 \%$ error range. ${ }^{26}$

Lipski and coworkers evaluated a device manufactured by Tekscan (South Boston, MA, USA) and found it useful in determining the jaw bite force (Figure 4). ${ }^{11}$ It comprises of a pressure sensor, a computer and proprietary pressure measurement software. The sensor consists of layers of pressure sensitive films and adhesives connected to a circuit (Figures 4-6). As the bite force increases, the electronic resistance decreases, and this is measured and converted to

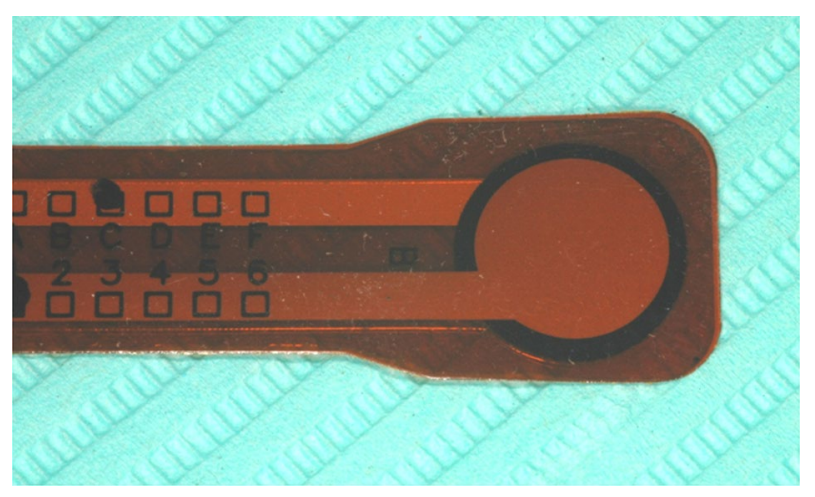

Figure 4 The pressure sensor.

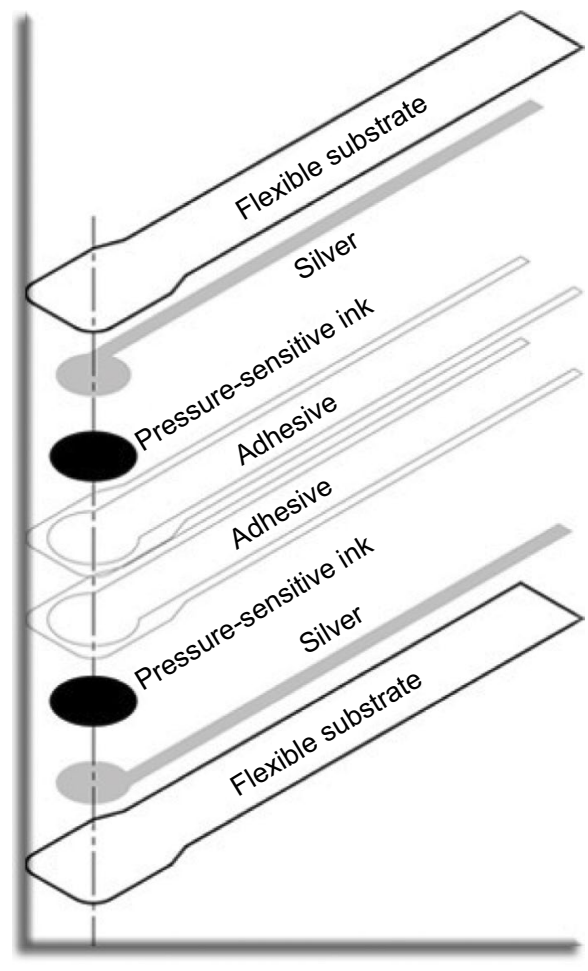

Figure 5 Schematic of sensor construction. Notes: Image courtesy of Tekscan, Inc.

newtons (Figures 7 and 8). The pressure sensor is sheathed in a plastic sleeve for contamination control (Figure 9). The device is positioned on or very near the arch site of the proposed implant (Figure 9). After cajoling the patient into a relaxed normalized jaw position, the patient is then asked to gradually bite down on the sensor with as much force as they can. Patients may not be able to exert their true maximum biting force for various reasons. ${ }^{11}$ Several readings may be needed to insure consistency. Patients need to ease their muscle contraction before they feel discomfort. The load value in newtons is then displayed by the software, and this is recorded in the patient's chart.

In an in vitro study, Rottner and coworkers found that a piezoelectric transducer foil of 33 microns thick can accurately measure the biting force. ${ }^{27}$ These use the pressuredependent electric resistance quality of the piezoelectric foil to measure the biting load. These subjects were instructed to bite down as hard as they could for 1 second. They found that occlusal morphology influenced the results. Cusp angles caused a wedging effect that gave higher measurements. ${ }^{27}$ Because of differing occlusal morphology individual calibration of the device is required for accuracy. ${ }^{27}$ Thus, any measuring device needs a sensor design that eliminates individual wedging occlusal tooth anatomy as a confounding factor.

Jaw force measurements may need to be normalized with electromyography to a maximal voluntary bite before 


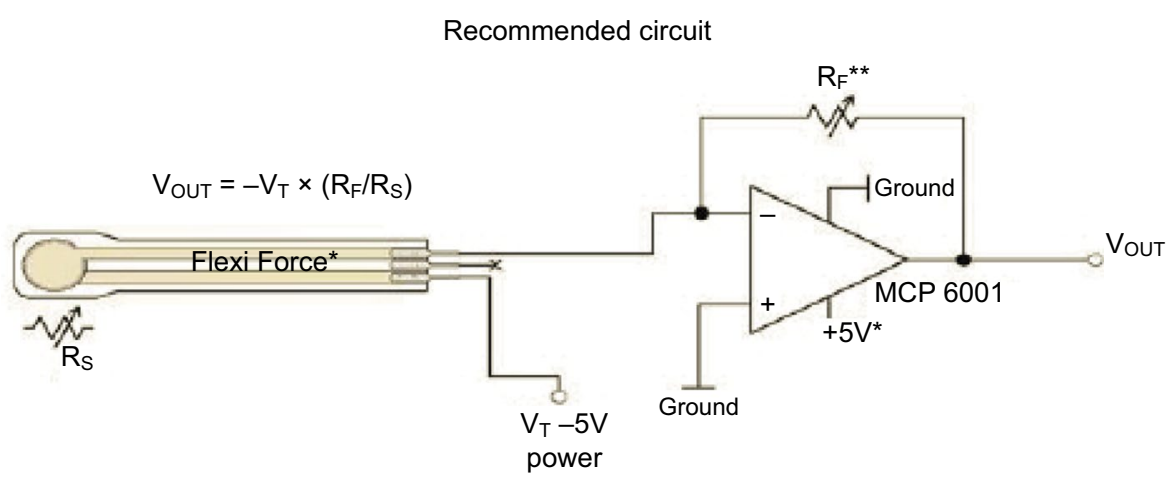

- * Supply voltages should be constant

- ** Reference resistance $R_{F}$ is $1-100 \mathrm{k} \Omega$

- Sensor resistance $R_{S}$ at no load is $>5 M \Omega$

- Maximum recommended current is $2.5 \mathrm{~mA}$

Figure 6 Circuitry of a sensor.

Notes: Image courtesy of Tekscan, Inc.

Abbreviations: $\mathrm{V}_{\text {out }}$, voltage out; $\mathrm{V}_{\mathrm{T}}$, voltage transfer power source.

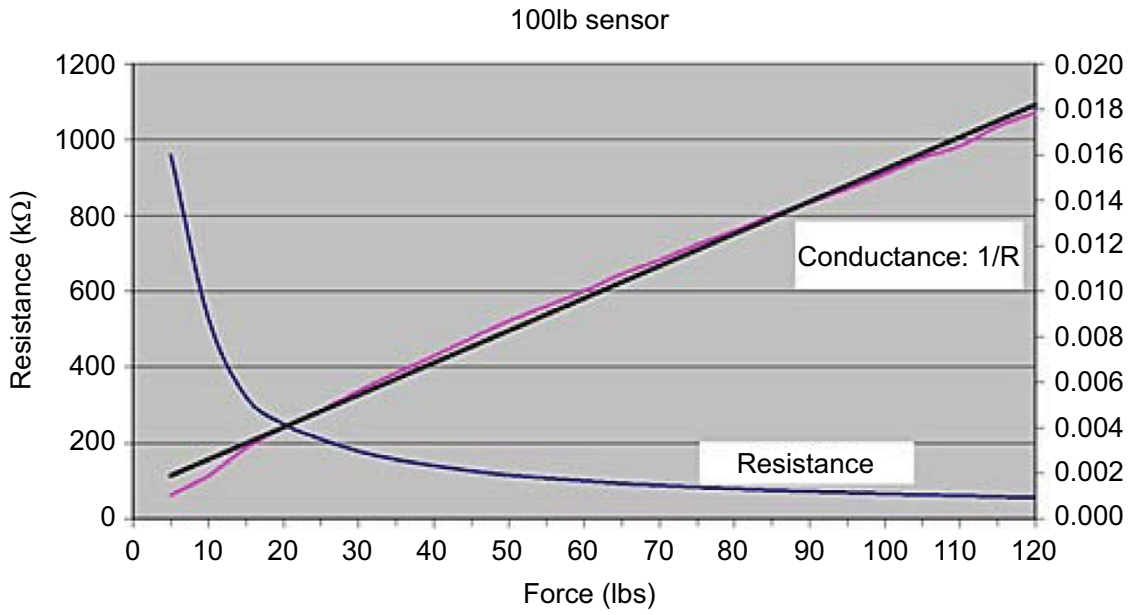

Figure 7 As the force on the sensor increases, the electronic resistance decreases, and this is measured. Notes: Image courtesy of Tekscan, Inc.

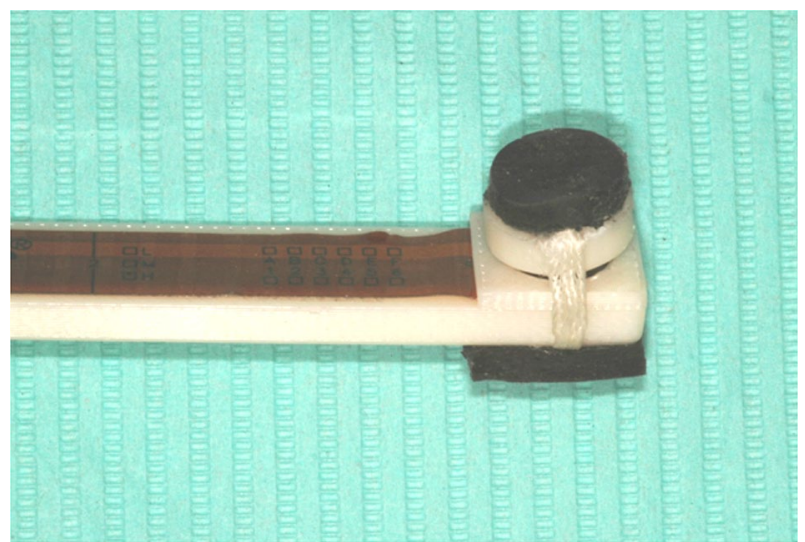

Figure 8 The pressure sensor with cushioned flexible pads to allow for accurate biting registration.

measurement to insure an accurate reading; otherwise, maximal bite force values may be distorted by uncoordinated muscle activity. ${ }^{28}$ Surface electromyography may eliminate a confounding muscle issue for bite force recordings. ${ }^{29} \mathrm{Soft}$

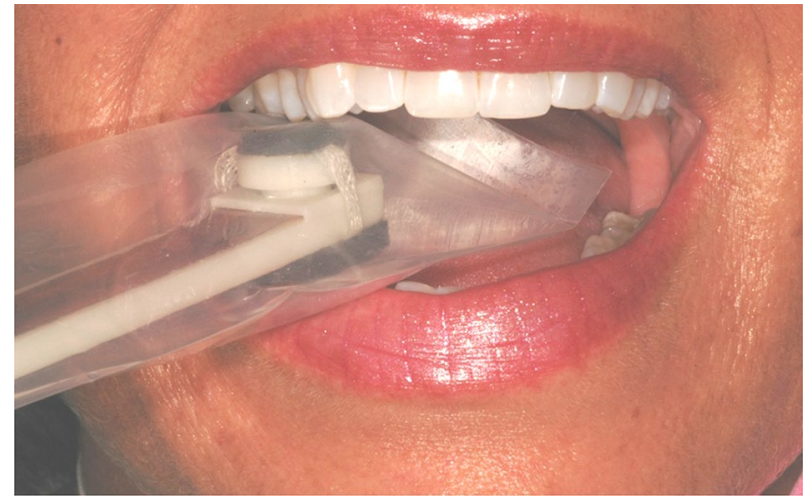

Figure 9 The pressure sensor is placed in the patient's mouth in the site where the loading will occur and the patient is instructed to bite with maximum force. Note: A plastic sleeve allows the reuse of the sensor apparatus.

bite surfaces on the sensors are needed for reliability when measuring the maximum voluntary bite force. ${ }^{30}$

The load value measurement is evaluated in relation to the range of reported human bite forces. A clinical judge- 
ment can then be made about occlusal scheme, the number of implants and size, splinting and implant positioning. The range of a human jaw biting force is $50-800 \mathrm{~N} .{ }^{1}$ If the patient is measured at the high end of this range, then planning may need to include: ridge splitting expansion to increase bone volume, additional implants and splinting for support, narrow flat plane occlusal tables, anterior guided occlusal scheme, parafunction and dietary considerations. ${ }^{7}$ Extracortical bone grafting may not provide as much support as a ridge-expanded site. ${ }^{7}$ Patients at the low end of the bite force range probably need no preemptive prosthetic design features. Although implant-supported maxillary anterior prosthetics especially need to be designed with occlusal loads in mind. ${ }^{7}$

Bruxism during sleep was measured by Nishigawa and coworkers. ${ }^{31}$ They found a nocturnal mean amplitude of 22.5 kilogram-force (kgf) with a mean duration of 7.1 seconds. ${ }^{31}$ The average daytime force measured on the subjects was $79.0 \mathrm{kgf}$ with a range of 51.8-99.7 kgf. Thus, the nocturnal bruxism force was $53.1 \%$ of the daytime generated force. However, a few subjects did generate a higher magnitude of nocturnal bruxing force than daytime generated voluntary bite force. ${ }^{31}$

\section{Conclusions}

Bite force may be an important parameter in implant selection and prosthetic case planning especially in patients who are capable of delivering very high occlusal loads. Since the facial cortical bone may be at most risk for overload and subsequent implant failure, the magnitude of the patient's bite force may be an issue for a long-term successful outcome, especially in maxillary anterior prostheses. There are available devices and methods that provide a convenient way to measure the generated load of a patient.

Bite force may be an important planning parameter. A patient that generates an excessive load may need to have the implant size and the number and occlusal design features that can adequately resist the load.

A high bite force capability may indicate a high risk for a late component fracture. Multiple or wide or long implants, implant positioning, an anterior guided occlusal scheme, splinting and ridge expansion augmentation, as opposed to extracortical grafting, may be considered to increase the osseous support or deflect or minimize the occlusal load. A patient with low biting force may be able to have a successful long-term outcome even with poor anatomical bone qualities.

Nonetheless, at this time, there is no correlation of any bite force value that would indicate any overload of any particular implant in any particular osseous site.

\section{Acknowledgments}

The author has no interest, financial or otherwise, of any of the products and methods discussed herein. All images are taken from the patients record and written informed consent for treatment and medical education was obtained for this study. All images were obtained with permission from the commercial entities involved.

\section{Disclosure}

The author reports no conflicts of interest in this work.

\section{References}

1. Fernandes CP, Glantz PO, Svensson SA, Bergmark A. A novel sensor for bite force determinations. Dent Mater. 2003;19(2):118-126.

2. Dan H, Kohyama K. Interactive relationship between the mechanical properties of food and the human response during the first bite. Arch Oral Biol. 2007;52(5):455-464.

3. Peixoto CD, Almas K. The implant surface characteristics and periimplantitis. An evidence-based update. Odontostomatol Trop. 2016; 39(153):23-35.

4. Demenko V, Linetskiy I, Linetska L, et al. Prognosis of implant longevity in terms of annual bone loss: a methodological finite element study. Comput Methods Biomech Biomed Eng. 2016;19(2):180-187.

5. Flanagan D. Diet and implant complications. J Oral Implantol. 2016;42(3):305-310.

6. Mesko ME, Almeida RC, Porto JA, Koller CD, da Rosa WL, Boscato N. Should occlusal splints be a routine prescription for diagnosed bruxers undergoing implant therapy? Int J Prosthodont. 2014;27(3):201-203.

7. Nagasawa M, Takano R, Maeda T, Uoshima K. Observation of the bone surrounding an overloaded implant in a novel rat model. Int J Oral Maxillofac Implants. 2013;28(1):109-116.

8. Ben-Gal G, Lipovetsky-Adler M, Haramaty O, Sharon E, Smidt A. Existing concepts and a search for evidence: a review on implant occlusion. Compend Contin Educ Dent. 2013;34 Spec No:26-31;quiz 32.

9. Spray JR, Black CG, Morris HF, Ochi S. The influence of bone thickness on facial marginal bone response: stage 1 placement through stage 2 uncovering. Ann Periodontol. 2000;5(1):119-128.

10. Flanagan D. Jaw bite force measuring device. J Oral Implantol. 2012; 38(4):361-364.

11. Lipski T, Kijak E, Witaszek E, Gaska D, Margielewicz J. Application of dental dynamometer in biomechanics. J Meas Eng. 2015;3(1): $17-22$.

12. Waltimo A, Könönen M. A novel bite force recorder and maximal isometric bite force values for healthy young adults. Scand J Dent Res. 1993;101(3):171-175.

13. Mosnegutu A, Wismeijer D, Geraets W. Implant-supported mandibular overdentures can minimize mandibular bone resorption in edentulous patients: results of a long-term radiologic evaluation. Int J Oral Maxillofac Implants. 2015;30(6):1378-1386.

14. Janovic A, Saveljic I, Vukicevic A, et al. Occlusal load distribution through the cortical and trabecular bone of the human mid-facial skeleton in natural dentition: a three-dimensional finite element study. Ann Anat. 2015;197:16-23.

15. Kleinfelder JW, Ludwigt K. Maximal bite force in patients with reduced periodontal tissue support with and without splinting. $J$ Periodontol. 2002;73(10):1184-1187.

16. Santana-Mora U, Martínez-Ínsua A, Santana-Penín U, del Palomar AP, Banzo JC, Mora MJ. Muscular activity during isometric incisal biting. J Biomech. 2014;47(16):3891-3897. 
17. Santana-Mora U, López-Cedrún J, Mora MJ, Otero XL, Santana-Penín U. Temporomandibular disorders: the habitual chewing side syndrome. PLoS One. 2013;8(4):e59980.

18. Yamanishi Y, Yamaguchi S, Imazato S, Nakano T, Yatani H. Effects of the implant design on peri-implant bone stress and abutment micromovement: three-dimensional finite element analysis of original computeraided design models. J Periodontol. 2014;85(9):e33-e338.

19. Tanasić I, Tihacek-Sojić L, Milić-Lemić A. Finite element analysis of compressive stress and strain of different implant forms during vertical loading. Int J Comput Dent. 2014;17(2):125-133.

20. Flanagan D, Ilies H, McCullough P, McQuoid S. Measurement of the fatigue life of mini dental implants: a pilot study. J Oral Implantol. 2008;34(1):7-11.

21. Chen KW, Lin TM, Liu PR, et al. An analysis of the implant-supported overdenture in the edentulous mandible. J Oral Rehabil. 2013; 40(1):43-50.

22. Flanagan D. A comparison of facial and lingual cortical thicknesses in edentulous maxillary and mandibular sites measured on computerized tomograms. J Oral Implantol. 2008;34(5):256-258.

23. Jofre J, Hamada T, Nishimura M, Klattenhoff C. The effect of maximum bite force on marginal bone loss of mini-implants supporting a mandibular overdenture: a randomized controlled trial. Clin Oral Impl Res. 2010;21:243-249.
24. Zhao X, Zhang L, Sun J, Yang ZY, Xie QF. Three-dimensional finite element analysis of influence of occlusal surface height on stress distribution around posterior implant-supported single crown. Beijing Da Xие Хие Bao. 2016;48(1):94-100.

25. Umesh S, Padma S, Asokan S, Srinivas T. Fiber Bragg grating based bite force measurement. J Biomech. 2016;49(13):2877-2881.

26. Lin $\mathrm{KR}$, Chang $\mathrm{CH}$, Liu TH, Lin SW, Lin CH. Experimental and numerical estimations into the force distribution on an occlusal surface utilizing a flexible force sensor array. J Biomech. 2011;44(10):1879-1884.

27. Rottner K, Richter EJ. Effect of occlusal morphology on the accuracy of bite force measurements using thin film transducers. Int J Prosthodont. 2004;17(5):518-523.

28. Crawford SR, Burden AM, Yates JM, Zioupos P, Winwood K. Can masticatory electromyography be normalised to submaximal bite force? J Oral Rehabil. 2015;42(5):323-330.

29. Ferrario VF, Sforza C, Zanotti G, Tartaglia GM. Maximal bite forces in healthy young adults as predicted by surface electromyography. J Dent. 2004;32(6):451-457.

30. Serra CM, Manns AE. Bite force measurements with hard and soft bite surfaces. J Oral Rehabil. 2013;40(8):563-568.

31. Nishigawa K, Bando E, Nakano M. Quantitative study of bite force during sleep associated bruxism. J Oral Rehabil. 2001;28(5): 485-491.
Medical Devices: Evidence and Research

\section{Publish your work in this journal}

Medical Devices: Evidence and Research is an international, peerreviewed, open access journal that focuses on the evidence, technology, research, and expert opinion supporting the use and application of medical devices in the diagnosis, monitoring, treatment and management of clinical conditions and physiological processes. The identification of novel
Dovepress

devices and optimal use of existing devices which will lead to improved clinical outcomes and more effective patient management and safety is a key feature. The manuscript management system is completely online and includes a quick and fair peer-review system. Visit http://www. dovepress.com/testimonials.php to read real quotes from authors.

Submit your manuscript here: https://www.dovepress.com/medical-devices-evidence-and-research-journal 